\begin{abstract}
Title of Document:

LEARNING TO COMMUNICATE RISK INFORMATION IN SOCIAL GROUPS

Hsuchi Ting, M.A., 2007

Directed By:

Professor T. S. Wallsten, Department of

Psychology

Despite vigorous research on risk communication, little is known about the social forces that drive these choices. Erev, Wallsten, \& Neal (1991) showed that forecasters learn to select vague or precise risk estimations as a function of what best serves the group's collective interests. This study extends the notion and further investigates whether evaluation apprehension contributes to the selection of the risk expressions. We hypothesize that group size and public feedback can engender apprehension and affect the learning of risk communication. Experiment 1 reproduced Erev et al.'s (1991) results and in addition showed that forecasters in small groups learned the optimal mode faster than those in larger groups. Experiment 2 contrasted social versus personal feedback and showed learning was faster in the personal feedback condition.
\end{abstract}




\title{
LEARNING TO COMMUNICATE RISK INFORMATION IN SOCIAL GROUPS
}

\author{
By
}

Hsuchi Ting

Thesis submitted to the Faculty of the Graduate School of the University of Maryland, College Park, in partial fulfillment of the requirements for the degree of Master of the Arts 2007

Advisory Committee:

Professor Thomas Wallsten, Chair

Professor Michael Dougherty

Professor Kent Norman 
(C) Copyright by Hsuchi Ting 2007 


\section{Acknowledgements}

I would like to thank all committee members, Drs. Thomas Wallsten, Mike Dougherty, and Kent Norman, for their helpful comments and numerous changes made on earlier drafts. The final product is regrettably unable to demonstrate the full extent of their insights and careful suggestions. More importantly, they agreed to discuss my proposal within one week, which showed true dedication to graduate students. I would also like to thank Robyn Zakalik for resolving the problems with withdrawing research funds needed to pay the participants, a process that still very much baffled me to this day. 


\section{TABLE OF CONTENTS}

Acknowledgements

List of Tables

List of Figures

CHAPTER 1. INTRODUCTION 1

CHAPTER 2: METHOD 4

EXPERIENT 1........................................................... 4

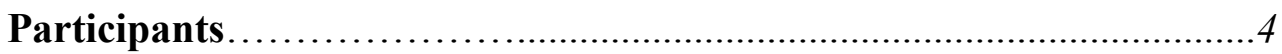

Design ......................................................4

Stimulus, Materials, and Procedure...............................4

Results: Forecast Mode as a Function of Trial Block..................8

Results: Sensitivity to the Payoffs of Others...................... 9

Discussion........................................................ 10

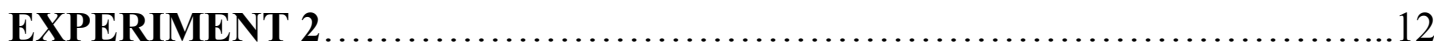

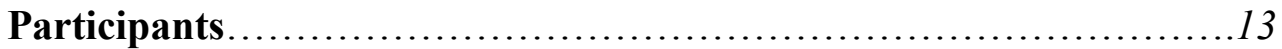

Design ...........................................................

Stimulus, Materials, and Procedure...............................13

Results.........................................................

Discussion .................................................. 15

CHAPTER 3: GENERAL DISCUSSION AND CONCLUSION 16

Further Issues and Future Directions...........................18

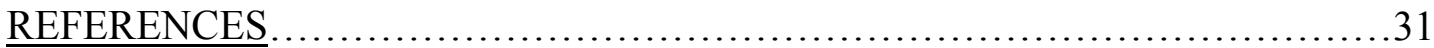




\section{List of Tables}

Table 1: $\quad$ Mean Slope Coefficients as a Function of Second-Order

Payoff and Group Size in Experiment 1.........................20

Table 2: $\quad$ Stepwise regression analysis predicting the linguistic

Preference...............................................21

Table 3: $\quad$ Mean Slope Coefficients as a Function of Second-Order

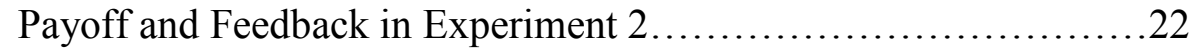




\section{List of Figures}

Figure 1: $\quad$ A Sample Spinner in the Experimental Design.....................23

Figure 2: $\quad$ Decision Sheet for Participant 1 in Large Group condition.............24

Figure 3: $\quad$ A: Proportion of precise terms used $( \pm \mathrm{SE})$ as a function of trial blocks in the homogeneous payoff condition in Experiment 1. B: Proportion of precise terms used $( \pm \mathrm{SE})$ as a function of trial blocks in heterogeneous payoff condition in Experiment $1 \ldots \ldots \ldots \ldots \ldots \ldots \ldots . . \ldots 25$

Figure 4: $\quad$ Proportion of optimal terms used $( \pm \mathrm{SE})$ as a function of trial blocks across both payoff conditions in Experiment $1 . \ldots \ldots \ldots \ldots \ldots \ldots \ldots . . . \ldots 26$

Figure 5: $\quad$ Mean of Precise Estimates Used as a Function of Averaged SecondOrder Payoff of the Same Group on the Previous Trial Block in Experiment 1 ........................................27

Figure 6: Decision sheet in Experiment 2...............................28

Figure 7: $\quad$ A: Proportion of precise terms used $( \pm \mathrm{SE})$ as a function of trial blocks in the homogeneous payoff condition in Experiment 2. B: Proportion of precise terms used $( \pm \mathrm{SE})$ as a function of trial blocks in heterogeneous payoff condition in Experiment 2.

Figure 8: $\quad$ Proportion of optimal terms used $( \pm \mathrm{SE})$ as a function of trial blocks

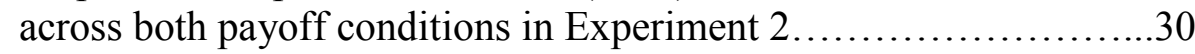




\section{Chapter 1. Introduction}

Literature on risk communication has stressed the role the public places on trust and reputation of the communication source (Siegrist \& Cvetkovich, 2000). Conversely, the form of the communication affects the trust placed in the communicator. For example, Gurmankin, Baron, and Armstrong (2004) found that patients put more faith in physician's diagnoses conveyed in numerical than in verbal terms. The bidirectional relationship between how risk information is communicated and the reputation of the source is an important issue to understand.

The focus of this research is to understand how forecasters choose to communicate risk information to others in the group. Absent from the literature on the linguistic preference of uncertainty communication is research on motivational factors behind the use of probabilistic estimates. Recognizing this shortcoming, Erev, Wallsten, and Neal (1991) suggested that in group contexts forecasters may select their communication modes in a manner that best serves society as a whole. They designed an experiment inspired by the tragedy of the commons (Hardin, 1968), in which individuals acting in their own self-interest collectively hurt or destroy their society. Markets (e.g., for stocks or futures) fail when everyone thinks that the same action is in his or her favor (e.g., everyone wants to sell). Conversely markets thrive when people prefer heterogeneous courses of action (some choose to buy and some to sell). Erev, Wallsten, and Neal (1991) asked whether forecasters (Fs) would select language that would induce heterogeneous or homogeneous behavior by decision makers as a function of what best served their group. To answer this question, they designed a study with two different payoff conditions. In one everyone in the group 
received a payoff when decision makers made the same (correct) choice and in the other condition everyone received a payoff when at least one decision-maker made the correct choice. In addition to possible group winnings, decision-makers won individual amounts when they were correct. Erev, Wallsten, and Neal (1991) assumed that (1) decision-makers make choices that they believe maximize their personal chances of winning and (2) individuals differ to a greater degree in interpreting verbal than numerical probabilities. On that basis they predicted that Fs would learn to give verbal judgments when heterogeneous behavior served the group's best interests (decision-makers acting in their self interest would make different choices, depending on their interpretations of the verbal terms) and numerical judgments when homogeneous behavior best served the group (all decision-makers would make the same, most likely choice). In fact, that is exactly how the data turned out. This finding suggests that forecasters do learn to adjust their precision of communication in response to group payoffs. However, drawing from the literature on group decisionmaking, we believe that impression management is also an important consideration to members of the same group. Ariely and Levav (2000) showed that decision-makers made sequential decisions based in part on how they would be perceived by others, oftentimes to the detriment of their personal satisfaction. The field experiments conducted by Ariely and Levav (2000) shared many similarities with the paradigm used by Erev et al. (1991). The most important feature was that people in the same group faced the same decision-making task, and that decision was made sequentially.

If people do indeed worry about how they appear to others in the group, then they will be motivated to avoid negative evaluations by acting in any way that can be 
construed as erroneous by members of their social group (Diehl \& Stroebe, 1987), a process known as evaluation apprehension. Evaluation apprehension is a feeling of arousal that curtails an individual's learning and performance when the individual is aware of the fact that his or her performance is being monitored. We hypothesize that people in salient roles such as communicating risk judgments are susceptible to such a process. However, the extent of the process depends on the size of the group (Green, 1991). Latané and his colleagues (Latané, 1981; Latané \& Hawkins, 1976) proposed a social impact model according to which feelings of apprehension within a group of similar status people increased as a function of group size. As a consequence, performance declined with group size. Similarly, people learned more effectively from their prior failures and mistakes when they were alone as compared to in the presence of an evaluative audience, and the reduction in the level of performance was the result of the evaluative anxiety caused by the bystanders and coactors (Seta \& Hassan, 1980; Seta, Seta, Donaldson, \& Wang, 1988).

Social impact model suggests evaluation apprehension arise when audience size grows, which is detrimental to learning and performance. Base on this logic, we hypothesize that the rate of development and convergence of risk communication pattern among group members is inversely related to group size. Specifically, group size moderates the rate of communication convergence, with increased size decreasing the rate of convergence, due to a heightened sense of evaluation apprehension. 


\section{Chapter 2: Method}

\section{Experiment 1}

\section{Participants}

A total of 171 participants from University of Maryland served in this study in exchange for monetary reward and course credit. Sixty participants served in groups of size 3 (small groups) while the remaining 111 served in groups of 5 or 6 (large groups). One group of 6 was excluded from the analysis due to violation of experimental protocol on communication.

\section{Design}

The study was a 2 (group size: small v. large) x 2 (payoff condition: heterogeneous v. homogeneous) x 10 (blocks of trials) mixed design with repeated measure on the last factor. Group members took turns serving as forecaster, decision-makers, and in the large group as bystanders. Thus, on every trial, regardless of group size, there was one forecaster and two decision-makers. Decision-makers individually won $\$ 0.15$ for each correct decision they made based on the judgments communicated by the forecaster. In addition to this first-order payoff, the decision-makers and in the large group the bystanders (but not the forecaster) received second-order payoffs according to which payoff condition they were in. In the homogeneous condition, decisionmakers and bystanders earned the second-order payoff of $\$ 0.10$ each whenever both decision-makers made the correct decision. In the heterogeneous condition, they received the second-order payoff as long as at least one decision-maker made the correct decision. A trial block was completed after everyone in the group had served as forecaster. The session continued for a total of 10 blocks.

\section{Stimulus, Materials, and Procedure}


Participants were seated around a large table with sufficient space between them that they could not see the decision form that each had in front of him or her. Two cubicles with computers and linked monitors opened to the room that housed the table. We first distributed written instructions describing the procedure and the payoff mechanism and then demonstrated them on the computer. Then, each participant received a number in a clockwise fashion. These numbers were written on a whiteboard so that a public record of each forecaster's performance could be kept. At this point we describe the procedure for the small groups only. The participant who received the number $1(\mathrm{P} 1)$ started the experiment as an forecaster while $\mathrm{P} 2$ and $\mathrm{P} 3$ served as decision-makers. On the first trial, P1 entered a separate cubicle to observe stimuli on the monitor and to make forecasts on the basis of them; only the forecaster had access to the stimuli. The experimenter monitored the stimuli (and the decisionmakers) from the other cubicle to make sure that forecaster followed the instructions correctly and did not intentionally mislead the decision-makers such as selecting terms that did not appear on the screen.

The stimuli consisted of various spinners radially divided into three colored sectors, red, blue, and yellow (see Figure 1). The three colors were named below the spinner and eight probability terms, four numerical and four verbal, were arrayed below each color name. All numerical values were chosen from the integer values in the range of \pm 2 from the actual proportion of the color on the spinner. Vague descriptors were selected from a list of phrases that appeared in Mosteller and Youtz (1990), in which the authors surveyed 20 studies and tabulated the numerical averages of opinions on quantitative meanings of 52 probabilistic expressions. We 
made a few changes to their list: first, we changed adverbs to adjectives; second, we deleted the two double negatives on the list (e.g. not unreasonable); leaving 50 terms available for this study. To reflect the wide individual differences that exist in interpreting verbal phrases, the four verbal phrases describing each color were randomly sampled from all available terms that were within the range of \pm 20 percentage points from the actual proportion of each color as found in Mosteller and Youtz (1990). The placement of verbal and numerical terms on screen was counterbalanced; half of the spinners had verbal descriptors listed before the numerical estimates, while other half had the opposite placement.

The decision forms had 30 numbered lines corresponding to the 30 trials of the session, each with RED, BLUE, and YELLOW written on it. Upon seeing the spinner on the monitor in the cubicle, forecaster selected one estimate for each color and called it out so that decision-makers could circle the color on the appropriate line of the decision form (Figure 2) that they believed the spinner would most frequently land on out of 6 spins. Then, forecaster clicked the left bar marked "Click to spin" and told the decision-makers the color the spinner landed on, forecaster repeated this spin procedure for a total of 6 times. Decision-makers then wrote down the number of times the color they selected came up in the 6 spins. For each correct response, decision-makers accumulated $\$ 0.15$ for themselves plus the amount of second-order payoff, determined by the payoff condition that Ps were in (homogeneous v. heterogeneous). The second-order payoff accumulated on that trial was a public record, recorded on the board next to the forecaster's assigned number. Finally, the 
trial ended when forecaster clicked the bar marked "Click for the next spinner" before exiting the cubicle.

The next trial started when P2 took the role of forecaster while P1 and P3 served as decision-makers. P2 repeated the same procedure as described above and then P3 took over the role of forecaster to begin the third trial. The process was repeated 30 times and every three trials made a trial block, totaling 10 trial blocks. Similar spinners appeared in each block save for slight changes in each color's proportion on the circle $( \pm 5$ percentage points).

In groups with sizes 5 and 6 , the procedure was identical except that a role of bystander was added. The order was designed so that decision-makers were always the next two members after forecaster, followed by the bystanders. For example, on trial 1, P1 began the experiment serving as forecaster, P2 and P3 became decisionmakers, while P4 to P6 (or P5 in groups of size 5) all took the role of bystanders. For the next trial, $\mathrm{P} 2$ became the forecaster and P3 and P4 were the decision-makers, etc. The role of bystander was added to keep the number of decision-makers constant across the size manipulation. Bystanders took no action but they received the same second-order payoff as did the decision-makers. Each trial block here was composed of 6(5) trials if there were 6 (5) members in the group, resulting in a total of 60 (50) trials for the whole experimental session.

At the end of the experiment, a true lottery was conducted using a bingo cage to determine the 2 trials that would count for cash payoffs. The payoff was the sum of personal winning earned when serving as decision-maker plus the second-order payoff on the trial selected for payment. In addition to the winnings from 
participation, participants in the heterogeneous condition could win an additional $\$ 1$ plus extra course credit if they finished first in earning, to reduce the possibility of collusion between participants.

\section{Results: Forecast Mode as a Function of Trial Block}

Our unit of analysis is groups, not individuals and our focus is on the proportions of numerical and verbal forecasts provided by Fs. We hypothesized that the use of precise estimates would increase in the homogeneous payoff condition and decrease in the heterogeneous, and furthermore, that the rates of change would be greater in the small than in the large group. Figure 3 showed the mean proportion of numerical forecasts as a function of trial block in each of the four group size-payoff condition combinations. Qualitatively, the effects all appear to be as predicted.

To assess the effects statistically, we fit separate linear and quadratic functions for each group to the scatter plot of proportion of numerical estimates as a function of trial block. The quadratic functions did not provide significantly better fits than the linear. Further, a 2 (group size) $\times 2$ (payoff) $\times 10$ (trial block) mixed analysis of variance (ANOVA) using the residuals from the linear fit for each group at each trial block as the dependent variable also revealed no systematic effects (all $F$ 's $<1.28$, all $p$ 's $>0.24)$. Hence, we used the slopes and intercepts of the linear functions as the dependent variables for subsequent group by condition analyses. Although our main interest is in the slopes as measures of rates of change, we first checked for any initial bias in the groups' linguistic choices by performing a $2 \times 2$ between-group ANOVA on the intercepts. No factors were significant (all $F$ 's $<1$ ). 
Next, we submitted the slopes to a 2 (group size) $\times 2$ (payoff) ANOVA. There was a significant effect due to payoff $\left[F(1,35)=31.27, \eta^{2}=.47, p<.001\right]$ as well as a payoff by group size interaction $\left[F(1,35)=5.04, \eta^{2}=.13, p<.04\right]$. We followed up the interaction with simple $t$-tests comparing groups within payoff conditions (Table 1). For participants in the homogenous payoff condition, the linear increase in the use of numerical estimates as a function of time was more pronounced in the small group $(M=.14, S E=.03)$ than in the large group $(M=.06, S E=.02)$ and the difference was significant $(t(18)=2.27, p<.04)$. In the heterogeneous condition, the linear decrease in the small group $(M=-.07, S E=.03)$ was also more pronounced than in large group $(M=-.03, S E=.02 ; t(17)=-1.03$, n.s. $)$, although the difference was not significant.

To highlight our main hypothesis that rate of learning the optimal communication mode is inversely related to group size we recoded the data to show the number of optimal communication mode choices in each trial block. We then fitted a linear function for each group to the scatter plot of proportion of optimal mode of choices as a function of trial block to obtain the slope for the dependent measure in a $2 \times 2$ between-group ANOVA. As predicted, the results showed that group size was the only significant factor $\left(\left(F(1,35)=4.74, \eta^{2}=.12, p<.04\right)\right.$. Figure 4 displays the mean proportion of optimal forecast mode choices as a function of trial block for both group sizes across payoffs.

\section{Results: Sensitivity to the Payoffs of Others}

For this analysis, we linearized the data in the same manner as before, except that the slopes and intercepts in this analysis came from regressing the proportion of numerical estimates used by all Fs in the current trial block as a function of the 
averaged second-order payoff accumulated by decision-makers in the previous trial block. Figure 5 showed the proportion of numerical estimates used in the current trial block conditioned on the second-order payoff of the previous trial block for all groups. A 2 (payoff) $\times 2$ (group size) ANOVA with the slopes from the linearized data as the dependent variable showed that main effects confirmed our hypothesis that forecaster's were affected by the performance in others: Payoff condition was significant, $F(1,35)=7.40, \eta^{2}=.15, p<.02$, showing that winnings from the prior trial affected subsequent forecaster's selection of a vague or precise expression. The group size factor was not significant $(F<1, n . s$.$) , nor was its interaction with payoff,$ $F(1,35)=3.05, p=.10$.

To further analyze the effect of group on individual performance, we performed a step-wise regression to examine whether learning was still significant after taking the outcome of prior trial block into account. Specifically, we first entered the main experimental factors (Group Size, Payoff, and Group Size x Payoff) into the regression. Then, the second step included the predictors Trial block, amount of winning in the previous round and its interaction with Payoff and Group Size. The results are displayed in Table 2. All factors in the second step other than the interaction of Group Size and previous winnings were significant and reached the $\alpha=$ .05 inclusion rule. The predictors Trial block $(B=0.22, p<.001)$ and prior SecondOrder Payoff $(B=1.06, p<.001)$ indicated a strong recency and learning effect in influencing the communication precision of the communicator.

\section{Discussion}


Consistent with our hypothesis, smaller groups showed a faster convergence and adaptation of the more advantageous form of risk communication pattern during the experiment than did the larger groups. The ANOVA results revealed that smaller groups used more precise form communication in the homogeneous payoff condition and more vague form when in the heterogeneous payoff condition as opposed to larger groups. Although the second ANOVA showed an overall group size effect on communication mode choice, the difference was significant only in the homogeneous payoff condition.

Erev et al. (1991) posited that the change in the precision of risk communication had a strong learning component as time progressed. However, evaluative apprehension predicts that Fs were also likely to be affected by the second-order payoff earned by their group. ANOVA revealed that forecaster's were influenced by the second-order payoffs received by the group. The regression analysis confirmed our ANOVA results in that monetary gains from the previous trial significantly influenced Fs' subsequent use of precise communication choices. Taken together, forecasters were sensitive not only to the structure of the group payoffs, but also to the outcomes attributed to the previous forecaster. This is consistent with previous research showing that social comparison heightens evaluative apprehension inside a group (Harkins, 1987; Leary, 1986), which is detrimental to performance.

Zajonc's (1965) social facilitation theory posits that the feeling of apprehension is expected when the task an individual has to perform is new. On the other hand, the presence of evaluator and audience can improve performance if the task he or she is required to perform has already been mastered. The social facilitation theory predicts 
that the presence of others can produce the arousal needed in social facilitation. Moreover, Zajonc (1980) asserted that the feeling of arousal is generated by the presence of any active evaluator or audience, especially when they are also performing the same task. This effect is known as the coactor effect which further shows that having to compare personal performance with others can result in poor performance.

It can be argued that the results in Exp. 1 are caused by competitive drive instead of evaluation apprehension. In our design, the co-actors performed risk forecasting, which allowed them to compete against one another for best results. Seta, Paulus, and Schkade (1976) found that individuals in big groups instead of small groups experienced poorer performance when engaged in competitive behavior. In light of this, we wish to test if the presence of co-actors can still reduce the adoption of optimal risk communication mode when there is no objective way for individuals to monitor the performance of others.

\section{Experiment 2}

In Experiment 1, we demonstrated that forecasters adopted the optimal mode of communication more slowly in larger groups even though doing so would confer a bigger payoff to the entire group. The forecaster's decision was also influenced by the results attributable to the previous forecaster, and this effect is accentuated in larger groups. The current experiment manipulates whether the second-order payoff information is social or personal. As discussed previously, social facilitation engenders evaluation apprehension when performance comparison is possible. This may muddle the interpretations in Exp.1 as the poorer performance in large group 
could be attributed to competition amongst group members instead of social facilitation. Experiment 2 manipulated the availability of the second-order payoff information to group members to test this possibility. If adoption of optimal communication mode is due to social facilitation, then the removal of payoff information from social groups should increase the proportion of precise terms used in the homogeneous payoff condition and decrease the proportion of precise terms used in the heterogeneous condition. If it is due to competition, then the reverse should occur. Specifically, we hypothesize that the payoff and its interaction with the availability of feedbacks should affect communication mode choices, with the direction of the interaction depending on the social pressure at work.

\section{Participants}

A total of 117 participants from University of Maryland served in 39 triads in exchange for monetary rewards and partial course credit.

\section{Design}

The study was a 2 (payoff: homogeneous v. heterogeneous) $\times 2$ (feedback: social v. personal) $\times 10$ (trial blocks) mixed design with repeated measure on the last factor.

\section{Stimulus, Materials, and Procedure}

Participants received the same stimuli and materials as those in the Experiment 1. The second-order payoff manipulation remained the same as in Experiment 1. The feedback condition manipulated the availability of information regarding the secondorder payoff winnings. In the personal feedback condition, only the forecaster received information on second-order earnings whereas all P's have the information in the social feedback condition, as described in Experiment 1. We kept the second- 
order earnings by recording the second-order earnings personally on the forecaster's decision sheet under the column marked "Forecaster Correct" (Figure 6). Each P had access only to the second-order payoff on trials in which he or she served as forecaster.

\section{Results}

Figure 7 shows the mean proportion of precise forecasts as a function of trial block in each of the four feedback-payoff condition combinations. As before, we fitted a linear function for each group to the scatter plot of proportion of numerical estimates as a function of trial block to obtain the intercept and slope. Table 3 summarizes the mean slope coefficients in the feedback and payoff condition. An initial ANOVA performed on the intercept found neither independent variable to be significant (all F's $<1.91$ ). Then, a separate ANOVA using slope as the dependent variable found no main effect of feedback $(F(1,35)=2.00, n$.s. $)$, but a significant effect of payoff condition $\left(F(1,35)=20.40, \eta^{2}=.37, p<.001\right)$ and a significant interaction between feedback and payoff, $\left(F(1,33)=4.79, \eta^{2}=.12, p<.04\right)$. We then performed simple t-tests comparing groups within payoff conditions. For participants in the homogenous payoff condition, the linear increase in the use of numerical estimates as a function of trial block for those in the social feedback $(M=.05, S E=.03)$ and those in the personal feedback $(M=.07, S E=.02)$ was not significantly different $(t(17)=$ $.59, n . s$.$) . In the heterogeneous condition, the linear decrease was greater in the$ personal feedback $(M=-.13, S E=.03)$ than in social feedback $(M=-.02, S E=.03)$ and the difference was significant, $t(16)=2.38, p<.03$. 
To highlight our main hypothesis that feedback affected the rate of learning the optimal mode of risk communication, we recoded the data to show the number of optimal communication choices in each trial block. We then fitted a linear function for each group to the scatter plot of proportion of optimal mode of estimates as a function of trial block to obtain the slope for dependent measure. As predicted, a $2 \mathrm{x}$ 2 between-group ANOVA showed the feedback condition was the only significant factor $\left(\left(F(1,33)=4.74, \eta^{2}=.13, p<.04\right)\right.$. Figure 8 shows the mean proportion of optimal mode of forecasts as a function of trial block for the both feedback conditions across payoffs.

\section{Discussion}

In Experiment 2, we tested whether eliminating group access to the information about second-order winnings can improve forecaster's communication. As predicted, the payoff and its interaction with feedback condition were both significant, suggesting that forecaster's were less worried about their performance when there was no basis for comparing their performance to that of the others.

Zajonc's (1965) social facilitation theory predicts that the level of performance drops when a person is confronted with a task that others are doing at the same time. On the other hand, the presence of evaluators and audience facilitates and improves individual performance if the task he or she is required to perform has already been mastered. This powerful theory has been replicated and observed in many contexts (for review, see Green, 1991) but never in risk communication. In Experiment 2, we found partial support for evaluation apprehension in risk communication as the forecaster adapted to the optimal mode of communication when feedback was 
masked. However, this effect was significant only in the heterogeneous payoff condition.

\section{Chapter 3: General Discussion and Conclusion}

Experiment 1 was designed to manipulate one's sense of evaluation apprehension, but the design did not allow us to rule out the possibility that performance was driven by a desire to compete. Experiment 2 tested that possibility by contrasting the effects of social and personal feedback on the rate of learning the optimal mode of communication. The results supported our hypothesis that evaluation apprehension could detract one from learning the optimal mode of risk communication as demanded by the payoff contingency.

The pattern of our results suggests that evaluation apprehension due to social facilitation had a negative affect on the formation of linguistic preferences. In Experiment 1, we demonstrated that the rate of learning the optimal mode of communication was higher when fewer members were affected and in Experiment 2, we showed that personal feedback was more effective in helping forecaster's to learn to communicate risk information than was public feedback. Because members of the same social group had strong interest in maintaining positive images, the adoption of a beneficial form of risk communication was predictably lower in conditions where evaluation apprehension was heightened, as in the case of large groups or the availability of the information on the performance of other members.

Following the position of by Fox and Irwin (1998) that the social contexts under which the uncertainty and risk communication take place should be experimentally examined, we studied the effects of social payoff (homogeneity v. heterogeneity in 
choices) and social comparison on the formation of the risk communication pattern. In Experiment 1, the size of the group had a negative impact on a forecaster's ability to adopt the optimal mode of communication called for by a payoff condition. Experiment 2 extended the finding by showing that presence of an audience can be made less detrimental when social feedback is muted.

Duval \& Wicklund (1972) proposed that the presence of others can cause an individual to focus more on personal performance and this leads to heightened awareness of personal performance and the ideal performance one wishes to obtain, which, in turn, can cause a decrement in performance (Liebling \& Shaver, 1973; Gibbons, 1990). The data we obtained appear to be inconsistent with the selfawareness account. The ANOVA and step-wise regression analyses in Experiment 1 showed that individual's risk communication pattern was influenced by the amount of second-order earnings made by other members in the group, suggesting that forecasters in Experiment 1 compared personal performance against same group members instead of focusing on how to achieve ideal performance forecasters had set for themselves.

The negative effect of audience is not restricted only to evaluative bystanders. Butler and Baumeister (1998) had found that a supportive audience could also cause a decrement in an individual's performance when the criterion of performance was set high. In studies on home-field advantage, Schlenker \& Leary (1982) found that supportive audiences made self-presentation need more salient thereby intensifying the level of self-focused attention. In a similar vain, Tesser and others (Tesser \& Campbell, 1982; Tesser, Campbell, \& McIntosh, 1989) found that supportive 
audiences made performer felt more scrutinized than non-supportive audience. In short, past literature suggests that the presence of others can reduce individual's level of performance when the results of performance can be checked.

\section{Further Issues and Future Directions}

Evaluation apprehension posits that the presence of coactors or evaluators is detrimental to an individual's performance if the task is new. However, it does not distinguish whether the apprehension stems from forecasters worrying about their own poor performance or about the good performance achieved by others in the same group. Past research on self-serving bias has found that when individuals had to compare their performance to that of others, they rated their personal performance more favorably rather than denigrating the others' performance. This effect was magnified when performance feedback was not produced after participants finished their task (Klein, 2001). The results were consistent with prior works on the effect of audience size on evaluation (Paulus \& Cornelius, 1974; Paulus, Shannon, Wilson, \& Boone, 1972; Seta \& Hassan, 1980) in that the performers in front of bigger audience tried harder to avoid poor performance than those with a smaller audience. Taken together, past results suggest that forecasters in our study were probably more concerned about how personal performance was being judged by coactors than trying to match performance achieved by other coactors. Future studies should explicitly manipulate the standards of performance and accessibility of feedback on performance to investigate the effect of social comparison on the development of risk communication pattern. 
Approaches in risk communication research in the past have been decidedly cognitive. While the cognitive approach has highlighted some fundamental differences in the numerical and verbal presentation of probabilistic events, it has ignored the context under which risk communication takes place, that is, in groups. In the group context, communicators have to consider not only their own communication preference, but also those of others. In medical situations, numerical presentation is the preferred mode of communication for the patient, and the physician's failure to take the patient's preference into consideration can result in poor decision-making on the part of the patient and an increased mistrust in the physician (Gurmankin, Baron, \& Armstrong, 2004). We think the current research offers some fresh considerations regarding risk communication in relevant social contexts. 
Table 1. Mean Slope Coefficients as a Function of Second-Order Payoff and Group

$\underline{\text { Size in Experiment } 1}$

\begin{tabular}{ccc}
\hline & \multicolumn{3}{c}{ Group Size } \\
\cline { 2 - 3 } Group Payoff & Small Group & Large Group \\
\hline Homogeneous & .14 & .06 \\
Heterogeneous & -.07 & -.03 \\
\hline
\end{tabular}


Table 2. Stepwise Regression Analysis Predicting the Linguistic Preference in

\section{Experiment 1}

\begin{tabular}{cccc}
\hline & $\mathrm{R}^{2}$ & Beta & $\mathrm{F}$ change \\
\hline First step & .21 & $.84^{*}$ & $\mathrm{~F}(3,347)=30.78^{* *}$ \\
Payoff & & $-1.19^{* *}$ & \\
Group Size & $.78^{* *}$ & \\
Payoff x Group Size & & & \\
& & & \\
Second step & .36 & $.22^{* *}$ & \\
Trial Block & & $1.06^{* *}$ & \\
Winning & & $-.13^{* *}$ & \\
Payoff x Trial Block & & $-.66^{* *}$ & \\
Payoff x Winning & & & \\
\hline
\end{tabular}

Note. Payoff $=$ Second-order payoff, homogeneous v. heterogeneous. Winning $=$ Averaged second-order payoff in the previous trial block. ${ }^{*} \mathrm{p}<.05 ;{ }^{* *} \mathrm{p}<.001$ 
Table 3. Mean Slope Coefficients as a Function of Second-Order Payoff and Feedback in Experiment 2

\section{Feedback}

\begin{tabular}{ccc}
\cline { 2 - 3 } Second-Order Payoff & Personal & Social \\
\hline Homogeneous & .07 & .05 \\
Heterogeneous & -.13 & -.02 \\
\hline
\end{tabular}


Figure 1. A Sample Spinner in the Experimental Paradigm.

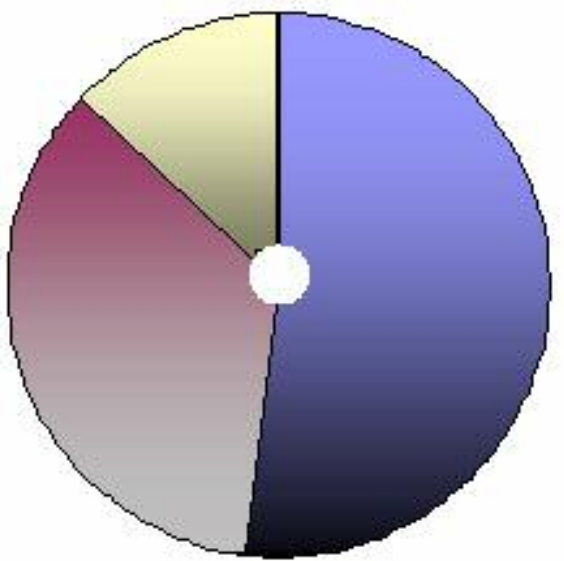

\section{Blue}

$53 \%$

$51 \%$

$54 \%$

$52 \%$

Probable

Frequent

As often as not

Often
Red

$35 \%$

$37 \%$

$33 \%$

$36 \%$

Less often than not Sometimes

Less than even

Mighthappen

\section{Yellow}

$14 \%$

$12 \%$

$11 \%$

$15 \%$

Veryirfrequent

Poor chance

Low probability

Once in a while

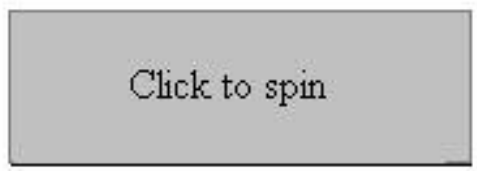

Click for next spinner 
Figure 2. Decision Sheet for Participant 1 in Large Group Condition

\begin{tabular}{|c|c|c|c|c|c|c|c|}
\hline Trial & Role & Participant 1 & Correct & Trial & Role & & Correct \\
\hline 1 & Forecaster & & & 31 & Forecaster & & \\
\hline 2 & Bystander & & & 32 & Bystander & & \\
\hline 3 & Bystander & & & 33 & Bystander & & \\
\hline 4 & Bystander & & & 34 & Bystander & & \\
\hline 5 & $\begin{array}{l}\text { Decision- } \\
\text { Maker }\end{array}$ & Blue Red Yellow & & 35 & $\begin{array}{l}\text { Decision- } \\
\text { Maker }\end{array}$ & Blue Red Yellow & \\
\hline 6 & $\begin{array}{l}\text { Decision- } \\
\text { Maker }\end{array}$ & Blue Red Yellow & & 36 & $\begin{array}{l}\text { Decision- } \\
\text { Maker }\end{array}$ & $\begin{array}{lll}\text { Blue } & \text { Red } \\
\end{array}$ & \\
\hline & & & & & & & \\
\hline 7 & Forecaster & & & 37 & Forecaster & & \\
\hline 8 & Bystander & & & 38 & Bystander & & \\
\hline 9 & Bystander & & & 39 & Bystander & & \\
\hline 10 & Bystander & & & 40 & Bystander & & \\
\hline 11 & $\begin{array}{l}\text { Decision- } \\
\text { Maker }\end{array}$ & Blue Red Yellow & & 41 & $\begin{array}{l}\text { Decision- } \\
\text { Maker }\end{array}$ & Blue Red Yellow & \\
\hline 12 & $\begin{array}{l}\text { Decision- } \\
\text { Maker }\end{array}$ & Blue $\quad$ Red $\quad$ Yellow & & 42 & $\begin{array}{l}\text { Decision- } \\
\text { Maker }\end{array}$ & Blue $\quad$ Red $\quad$ Yellow & \\
\hline & & & & & & & \\
\hline 13 & Forecaster & & & 43 & Forecaster & & \\
\hline 14 & Bystander & & & 44 & Bystander & & \\
\hline 15 & Bystander & & & 45 & Bystander & & \\
\hline 16 & Bystander & & & 46 & Bystander & & \\
\hline 17 & $\begin{array}{l}\text { Decision- } \\
\text { Maker }\end{array}$ & Blue Red Yellow & & 47 & $\begin{array}{l}\text { Decision- } \\
\text { Maker }\end{array}$ & $\begin{array}{lll}\text { Blue } & \text { Red } \\
\end{array}$ & \\
\hline 18 & $\begin{array}{l}\text { Decision- } \\
\text { Maker }\end{array}$ & Blue Red Yellow & & 48 & $\begin{array}{l}\text { Decision- } \\
\text { Maker }\end{array}$ & Blue $\quad$ Red $\quad$ Yellow & \\
\hline 19 & Forecaster & & & 49 & Forecaster & & \\
\hline 20 & Bystander & & & 50 & Bystander & & \\
\hline 21 & Bystander & & & 51 & Bystander & & \\
\hline 22 & Bystander & & & 52 & Bystander & & \\
\hline 23 & $\begin{array}{l}\text { Decision- } \\
\text { Maker }\end{array}$ & Blue Red Yellow & & 53 & $\begin{array}{l}\text { Decision- } \\
\text { Maker }\end{array}$ & Blue Red Yellow & \\
\hline 24 & $\begin{array}{l}\text { Decision- } \\
\text { Maker }\end{array}$ & $\begin{array}{lll}\text { Blue } & \text { Red } & \text { Yellow }\end{array}$ & & 54 & $\begin{array}{l}\text { Decision- } \\
\text { Maker }\end{array}$ & Blue $\quad$ Red $\quad$ Yellow & \\
\hline 25 & Forecaster & & & 55 & Forecaster & & \\
\hline 26 & Bystander & & & 56 & Bystander & & \\
\hline 27 & Bystander & & & 57 & Bystander & & \\
\hline 28 & Bystander & & & 58 & Bystander & & \\
\hline 29 & $\begin{array}{l}\text { Decision- } \\
\text { Maker }\end{array}$ & $\begin{array}{lll}\text { Blue } & \text { Red } & \text { Yellow }\end{array}$ & & 59 & $\begin{array}{l}\text { Decision- } \\
\text { Maker }\end{array}$ & Blue $\quad$ Red & \\
\hline 30 & $\begin{array}{l}\text { Decision- } \\
\text { Maker }\end{array}$ & Blue Red Yellow & & 60 & $\begin{array}{l}\text { Decision- } \\
\text { Maker }\end{array}$ & Blue $\quad$ Red & \\
\hline
\end{tabular}


Figure 3. A: Proportion of precise terms used $( \pm \mathrm{SE})$ as a function of trial blocks in the homogeneous payoff condition in Experiment 1. B: Proportion of precise terms used $( \pm \mathrm{SE})$ as a function of trial blocks in heterogeneous payoff condition in Experiment 1.
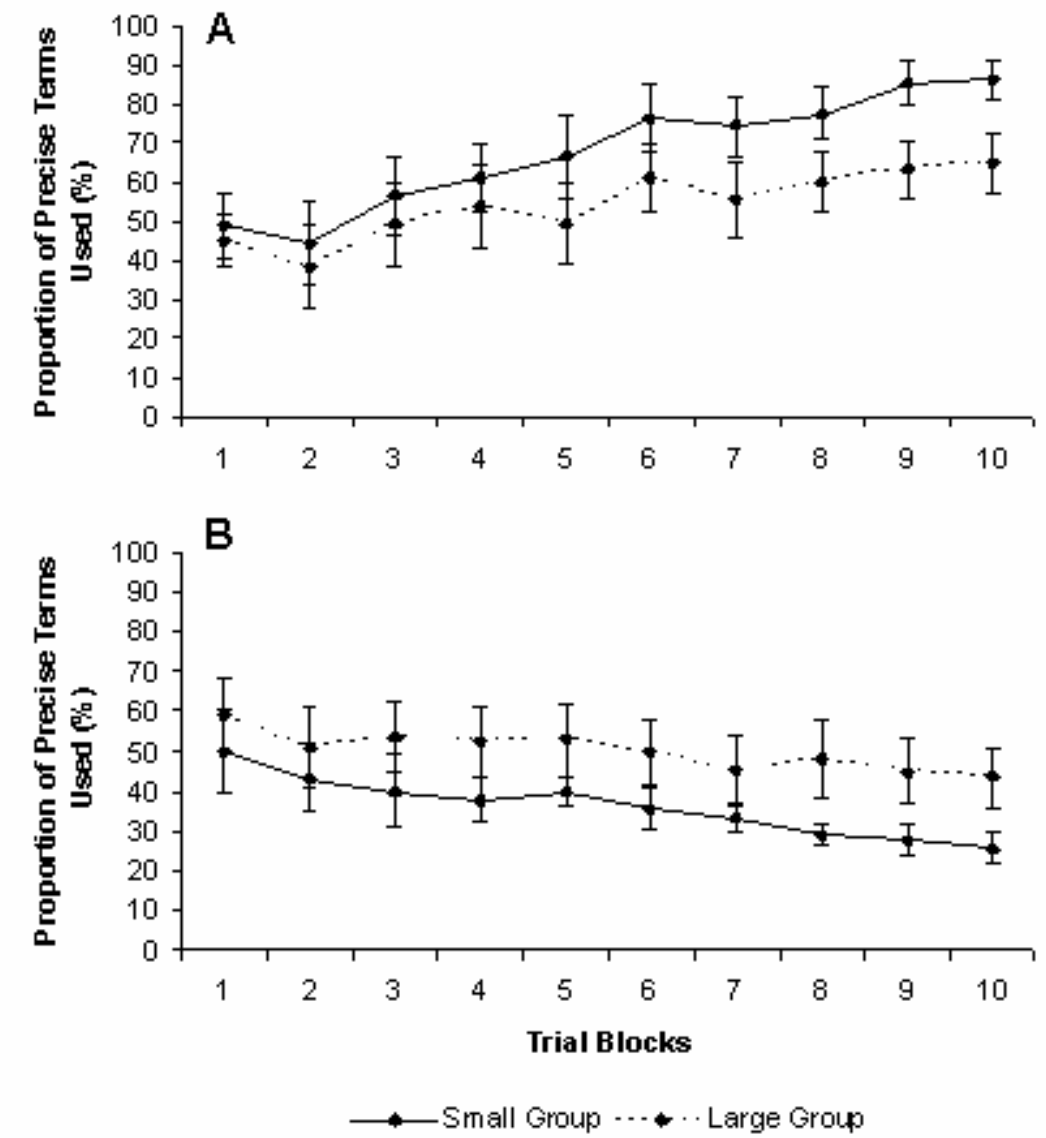
Figure 4. Proportion of optimal terms used $( \pm \mathrm{SE})$ as a function of trial blocks across both payoff conditions in Experiment 1.

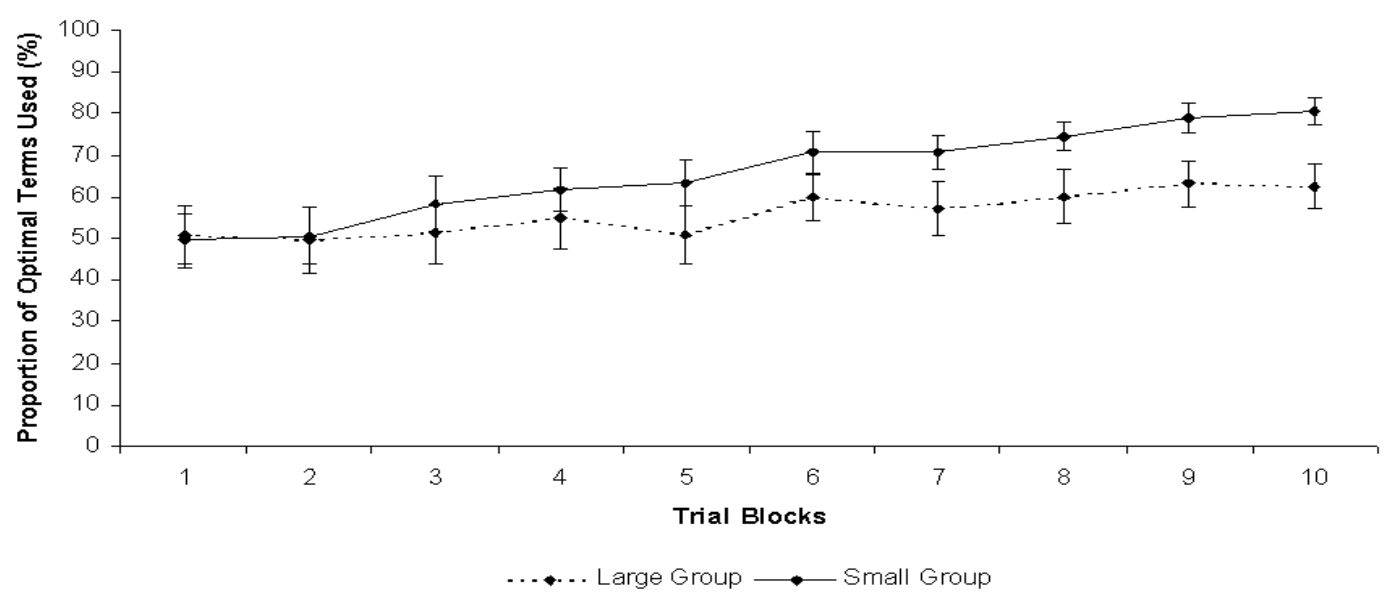


Figure 5. Mean of Precise Estimates Used as a Function of Averaged Second-Order Payoff of the Same Group on the Previous Trial Block in Experiment 1

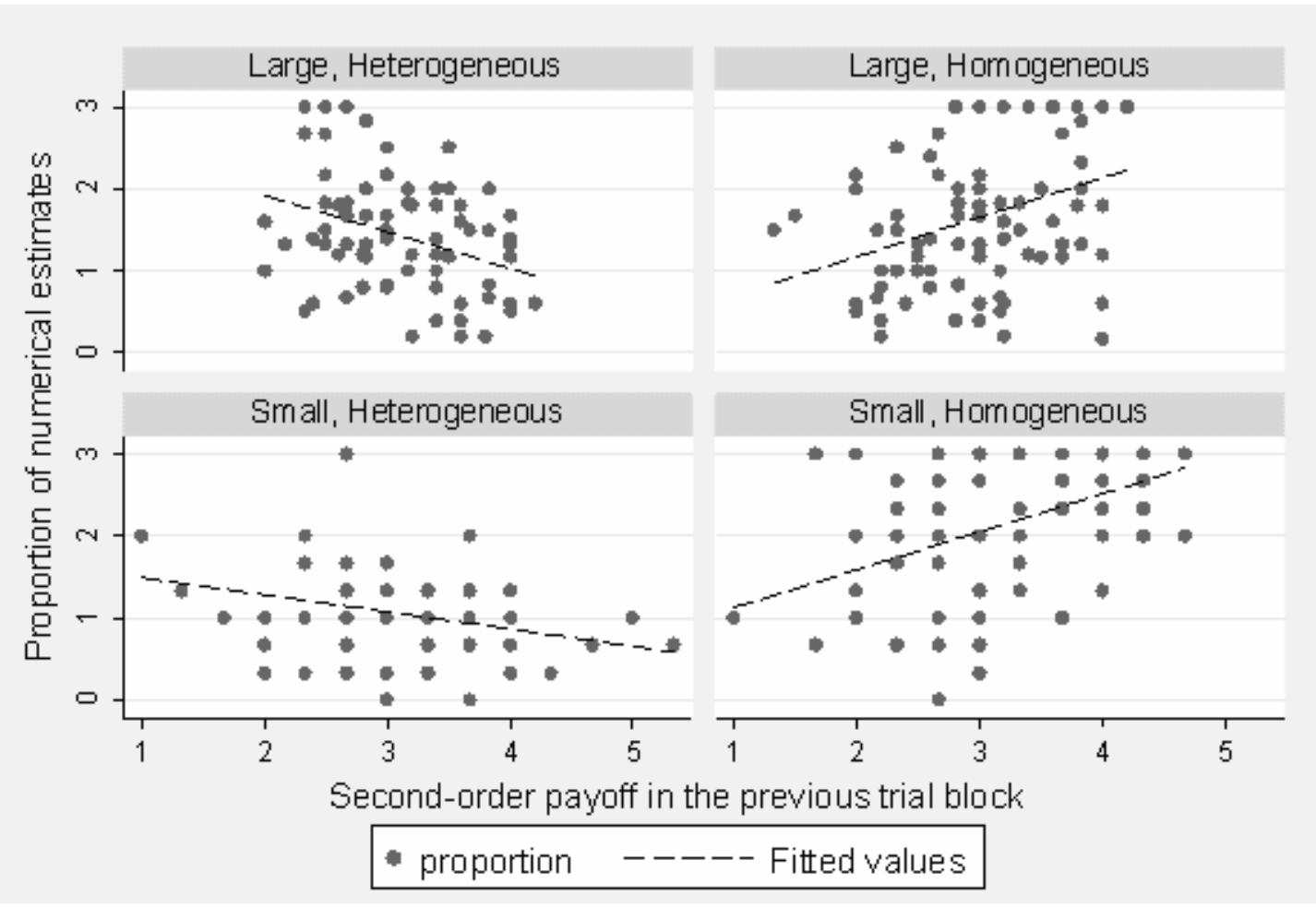


Figure 6. Decision sheet in Experiment 2

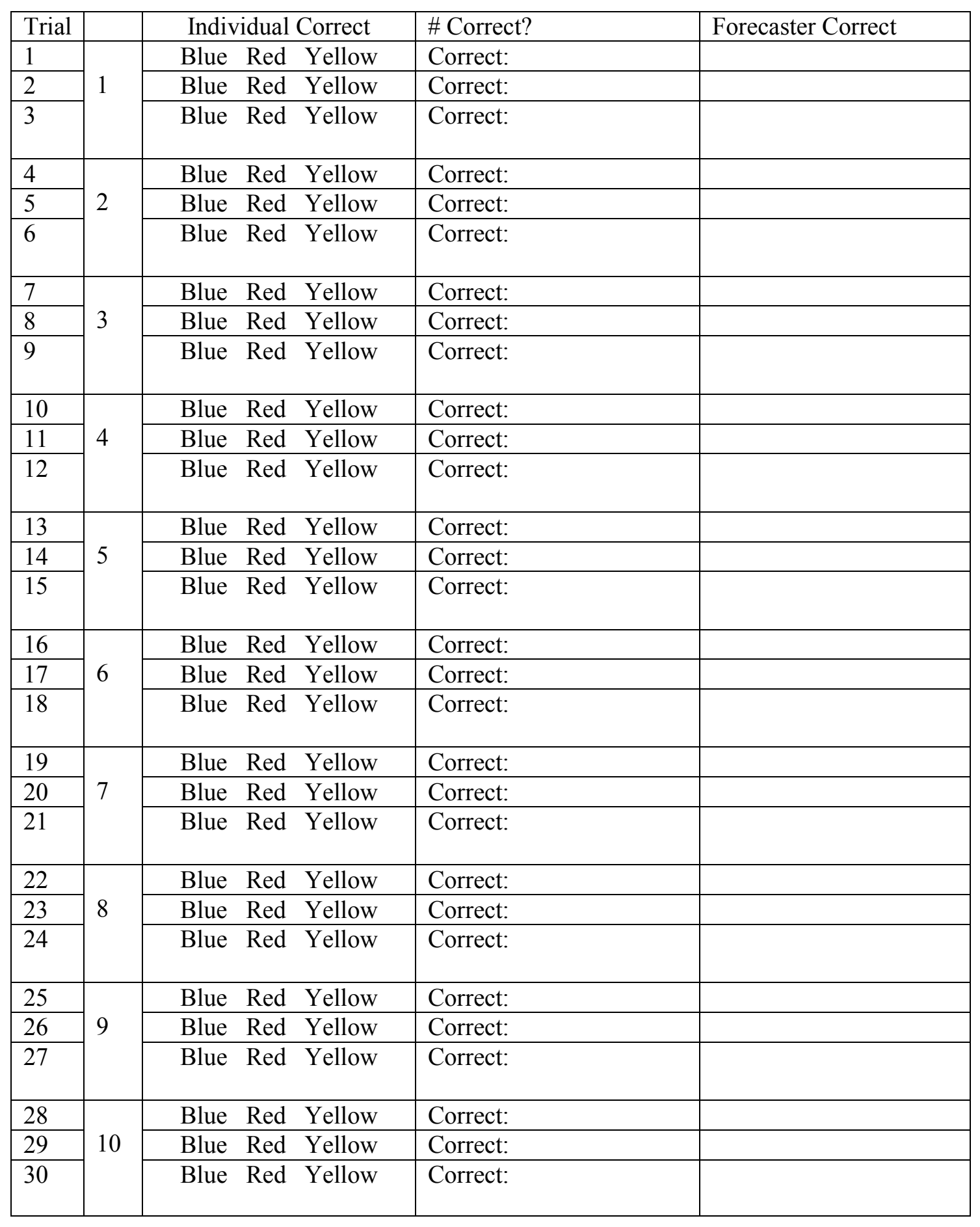


Figure 7. A: Proportion of precise terms used $( \pm \mathrm{SE})$ as a function of trial blocks in the homogeneous payoff condition in Experiment 2. B: Proportion of precise terms used $( \pm \mathrm{SE})$ as a function of trial blocks in heterogeneous payoff condition in Experiment 2.
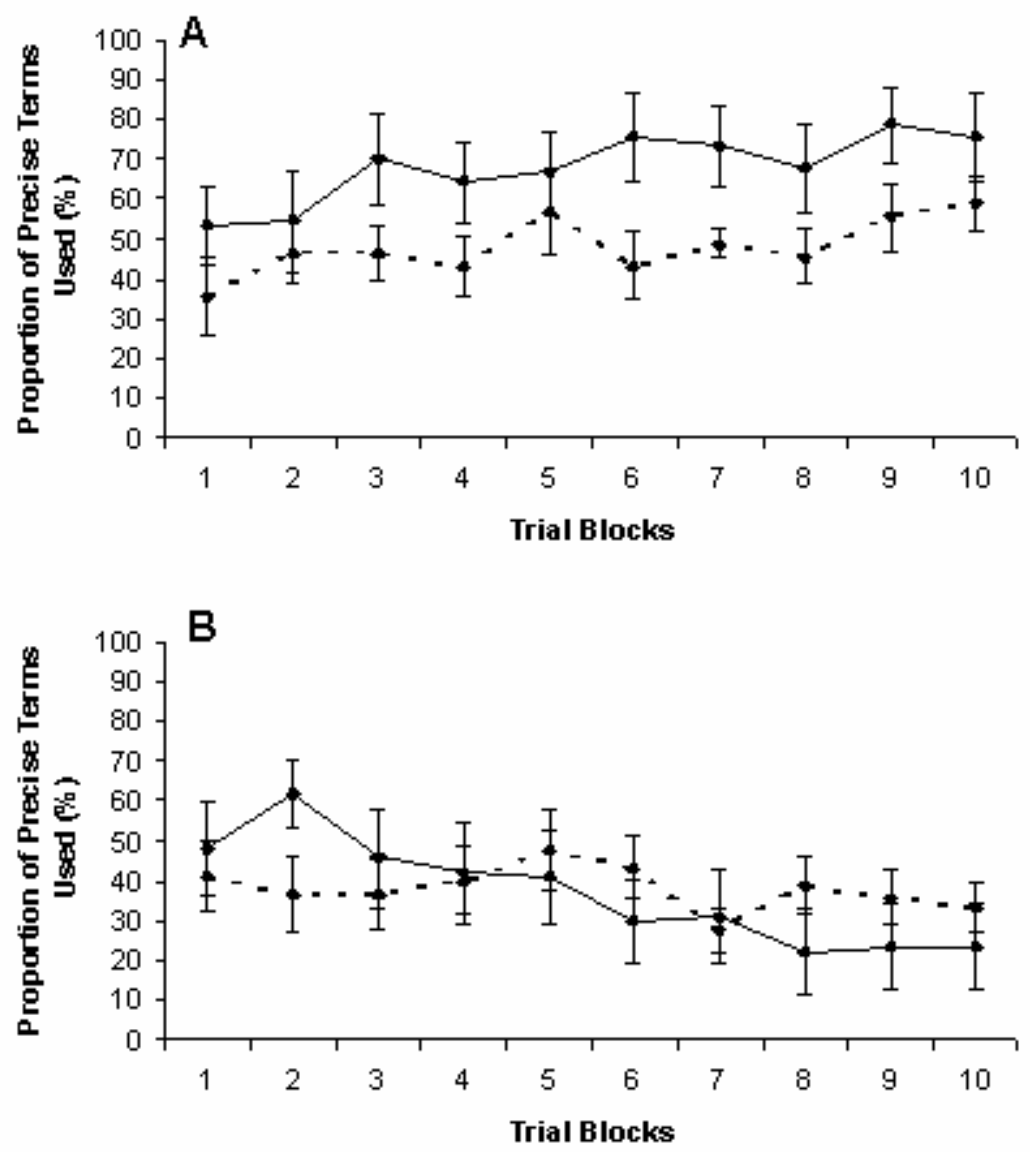

- -+- Social Feedback $\longrightarrow$ Personal Feedback 
Figure 8. Proportion of optimal terms used $( \pm \mathrm{SE})$ as a function of trial blocks across both payoff conditions in Experiment 2.

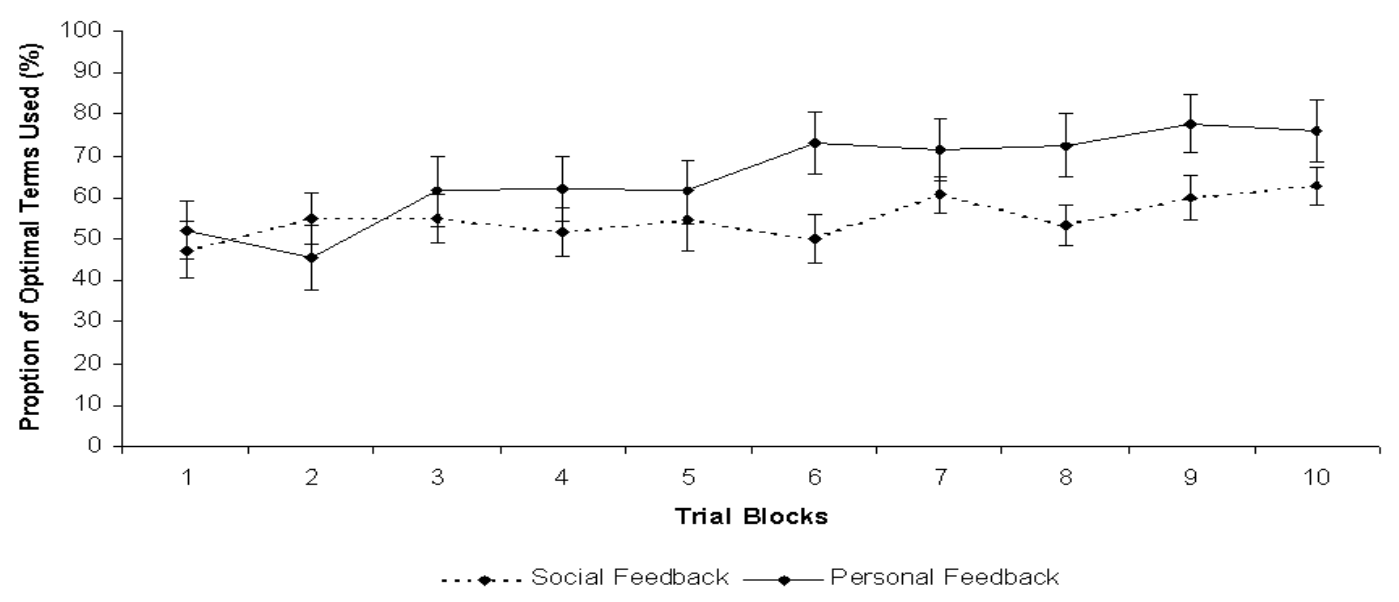




\section{Reference}

Ariely, D., Levav, J. (2000). Sequential choice in group settings: Taking the road less traveled and less enjoyed. Journal of Consumer Research, 27, 279-290.

Butler, J. L., Baumeister, R. F. (1998). The trouble with friendly faces: Skilled performance with a supportive audience. Journal of Personality and Social Psychology, 75, 1213-1230.

Diehl, M., \& Stroebe, W. (1987). Productivity loss in brainstorming groups: Toward the solution of a riddle. Journal of Personality and Social Psychology, 53, 497509.

Erev, I., Wallsten, T. S., \& Neal, M. M. (1991). Vagueness, ambiguity, and the cost of mutual understanding. Psychological Science, 2, 321-324.

Fox, C. R., \& Irwin, J. R. (1998). The role of context in the communication of uncertain beliefs. Basic and Applied Social Psychology, 20, 57-70.

Gibbons, F. X. (1990). Self-attention and behavior: A review and theoretical update. Advances in Experimental Social Psychology, 23, 249-303.

Green, R. G. (1991). Social motivation. Annual Review of Psychology, 42, 377-399.

Gurmankin, A.D., Baron, J., \& Armstrong, K. (2004). The effect of numerical statements of risk on trust and comfort with hypothetical physician risk communication. Medical Decision Making, 24, 265-271.

Hardin, G. (1968). The tragedy of the commons. Science, 162, 1243-1248.

Harkins, S. G. (1987). Social loafing and social facilitation. Journal of Experimental Social Psychology, 23, 1-18.

Klein, W. M. P. (2001). Post hoc construction of self-performance and other 
performance in self-serving social comparison. Personality and Social Psychology Bulletin, 27, 744-754.

Latané, B. (1981). The psychology of social impact. American Psychologist, 36, 343-356.

Latané, B., \& Harkins, S. G. (1976). Cross-modality matches suggest anticipated stage fright as multiplicative function of audience size and status. Perception and Psychophysics, 20, 482-488.

Leary, M. R. (1986). The impact of interactional impediments on social anxiety and self-presentation. Journal of Experimental Social Psychology, 22, 122-135.

Liebling, B. A., Shaver, P. (1973). Evaluation self-awareness and task performance. Journal of Experimental Social Psychology, 9, 297-306.

Mosteller, F., \& Youtz, C. (1990). Quantifying probabilistic expressions. Statistical Science, 5, 2-12.

Paulus, P. B., \& Cornelius, W. L. (1974). An analysis of gymnastic performance under conditions of practice and operator observation. Research Quarterly, 45, 5663.

Paulus, P. B., Shannon, V. C., Wilson, D. L., \& Boone, T. D. (1972). The effects of operator presence on gymnastic performance in a field situation. Psychonomic Science, 29, 88-90.

Schlenker, B. R., \& Leary, M. R. (1982). Audience's reactions to self-enhancing, selfdenigrating, and accurate self-presentations. Journal of Experimental Social Psychology, 18, 89-104.

Seta, C. E., Seta, J. J., Donaldson, S., \& Wang, M (1988). The effects of evaluation 
on organizational processing. Personality and Social Psychology Bulletin, 14, 604-609.

Seta, J. J., \& Hassan, R. K. (1980). Awareness of prior success or failure: A critical factor in task performance. Journal of Personality and Social Psychology, 39, 7076.

Seta, J. J., Paulus, P. B., \& Schkade, J. K. (1976). Effects of group size and proximity under cooperative and competitive conditions. Journal of Personality and Social Psychology, 34, 47-53.

Siegrist, M. and Cvetkovich, G. (2000) Perception of hazards: the role of social trust and knowledge, Risk Analysis, 20, 713-719.

Tesser, A., \& Campbell, C. J. (1982). Self-evaluation maintenance and the perception of friends and strangers. Journal of Personality, 50, 261-279.

Tesser, A., Campbell, C. J., \& McIntosh, W. D. (1989). Self-evaluation maintenance and the mediational role of emotion: The perception of friends and strangers. Journal of Personality and Social Psychology, 57, 442-456.

Zajonc, R. B. (1965). Social facilitation. Science, 16, 269-274.

Zajonc, R. B. (1980). Compresence. In P. B. Paulus (Ed.), Psychology of group influence (pp. 35-60). Hillsdale, NJ: Lawrence Erlbaum. 